\title{
DIFERENCIAS DE GÉNERO EN CUESTIÓN DE DERECHOS: UNA PERSPECTIVA DE ENFERMERÍA
}

\author{
GENDER DIFFERENCES REGARDING RIGHTS: A NURSING PERSPECTIVE
}

QUINTANA-ZAVALA MARÍA OLGA* JOFRÉ-ARAVENAVIVIANE**

\begin{abstract}
The purpose of this article is to analyze gender differences with respect to human, civil, labor, sexual, and reproductive rights, all of them from the nursing perspective. Herein, human rights are understood as universal guarantees that protect individuals and groups against acts and omissions that interfere with human freedoms and dignity. Civil rights are intended to protect human beings against any aggression from public agencies, asserting that all individuals have fundamental freedoms without distinction of race, sex, color, tongue, social or economic position; that individuals are entitled to the right to life, freedom, and legal certainty. Labor rights are essential elements of fundamental human rights; sexual and reproductive rights are related to men and women sexuality and reproduction. Equal rights are stipulated in multiple treaties, conventions, and legislations; however, there are differences in some laws, which indicate the androcentric perspective that was used to draft them. Thus, nursing profession is striving for the respect of human rights, for women and men, without discrimination of any type.
\end{abstract}

Key Words: Human Rights; Civil Rights; Sexual and Reproductive Rights; Nursing (DeCS).

\section{RESUMEN:}

E ste artículo tiene el propósito de analizar las diferencias de género en cuanto a los derechos humanos, civiles, laborales, sexuales y reproductivos, desde la perspectiva de enfermería, entendiendo a los derechos humanos como garantías universales que protegen a individuos y a grupos contra acciones y omisiones que interfieren con las libertades y la dignidad humana; los derechos civiles están destinados a la protección de los seres humanos contra cualquier agresión de un órgano público, aseveran, que toda persona tiene libertades fundamentales sin distinción de raza, sexo, color, idioma, posición social o económica y tiene derecho a la vida, a la libertad y a la seguridad jurídica; los derechos laborales son elementos indispensables de los derechos humanos fundamentales, tanto los civiles y políticos como los económicos, sociales y culturales; los derechos sexuales y reproductivos, se relacionan con la sexualidad y la reproducción de las mujeres y los hombres. La igualdad de derechos está estipulada en múltiples tratados, convenciones y legislaciones, sin embargo, existen diferencias concertadas en algunas leyes, lo que revela la perspectiva androcéntrica con la que fueron redactadas. La profesión de enfermería pugna por el respeto a los derechos de mujeres y hombres, sin discriminación de ningún tipo.

Palabras claves: Derechos Humanos; Derechos Civiles; Derechos Sexuales y Reproductivos; Enfermería (DeCS).

*Enfermera, Dr. en Enfermería, Profesora Titular, Jefa del Departamento de Enfermería de la Universidad de Sonora, México, e-mail: olga_quintana@enfermeria.uson.mx. Responsable de la correspondencia.

**Enfermera, Dr. en Enfermería, Profesora Titular, Decana de la Facultad de Enfermería de la Universidad de Concepción, Chile. 


\section{INTRODUCCIÓN}

Los derechos son inherentes a la naturaleza del ser humano, sin los cuales los individuos no podrían vivir en paz, no son solo tema de abogados(as), sino de toda la sociedad, ya que la cultura de respeto, conocimiento y cumplimiento de los derechos propios, permite a mujeres y hombres, ser activos (as), consientes y capaces de poner en práctica acciones para su defensa y protección,por lo que el análisis del tema, sirve para identificar cualquier tipo de discriminación o inequidad. ${ }^{(1,2)}$

Existen tratados internacionales, elaborados con el fin de promover el respeto a los derechos de la persona humana, como la Declaración Universal de los Derechos $\mathrm{Hu}$ manos, aprobada en 1948 por la Organización de las Naciones Unidas (ONU), donde se proclama la universalidad e indivisibilidad de todos los derechos humanos como dos condiciones esenciales para su eficaz puesta en práctica. La Convención Americana sobre los Derechos Humanos, denominada "Pacto de San José de Costa Rica", efectuada en 1969, donde los gobiernos participantes expresaron que reconocen la competencia de la Comisión Interamericana de los Derechos Humanos por tiempo indefinido y las constituciones políticas de los países, donde se declara que las personas nacen libres e iguales en dignidad y derechos ${ }^{(3)}$.

En el caso de Chile, se reconocen los derechos humanos, a partir de 1990, después de 17 años de dictadura militar, donde existieron prácticas represivas y en múltiples ocasiones fueron atropellados los derechos humanos fundamentales ${ }^{(4)}$. Después del regreso a la democracia y fundamentalmente durante el gobierno de Bachelet, se crearon organismos tendientes a buscar la igualdad entre mujeres y hombres en todos los niveles, como el Consejo de Ministros para la Igualdad entre Hombres y Mujeres, el Plan de Igualdad, el Plan de los Compromisos Ministeriales de Género y el Servicio Nacional de la Mujer (SERNAM), el último es una institución reconocida internacionalmente por su labor en materia de reformas legislativas, que coordina las políticas de género del Estado Chileno y coloca temas de género en la agenda pública ${ }^{(5,6)}$.

Pese a los organismos existentes y al discurso político instalado en Latinoamérica y en el mundo, en la actualidad todavía existen desigualdades entre mujeres y hombres, las cuales son intrínsecamente discriminatorias e injustas, por lo que es necesario poner especial atención a la igualdad de género ${ }^{(7)}$ en todos los ámbitos, por lo anterior, el presente escrito tiene el propósito de analizar las diferencias existentes entre mujeres y hombres en cuanto a los derechos humanos, civiles, laborales y sexuales, desde la perspectiva de enfermería.

\section{DESARROLLO}

\section{Derechos humanos}

"Los derechos humanos son garantías universales que protegen a individuos y a grupos, contra acciones y omisiones que interfieren con las libertades y los derechos fundamentales y con la dignidad humana. La legislación en materia de derechos humanos obliga, principalmente a los gobiernos, a hacer ciertas cosas y les impide hacer otras" (8). Se basan en los principios de igualdad, libertad y solidaridad, los cuales surgen de la Revolución Francesa y son recogidos en la Declaración Universal de los Derechos Humanos ${ }^{(9)}$ no existiendo diferencias teóricas en cuanto a género.

Sin embargo, existe evidencia de la lucha de las mujeres para defender sus derechos a través del tiempo, que dan a conocer las inequidades existentes en la sociedad, así como, la desventaja asociada al hecho de ser mujer, ya que las leyes han sido elaboradas desde una perspectiva androcéntrica. Al respecto, se destaca que la obra más antigua relacionada a la necesidad de equiparar los derechos de mujeres y hombres que data desde el siglo XVI escrita por María Lejars ${ }^{(1)}$, donde se evidencian las desigualdades palpables entre mujeres y hombres de aquella época.

Durante la Cuarta Conferencia Mundial sobre la Mujer se expresó que: "la igualdad entre mujeres y hombres es una cuestión de derechos humanos y constituye una condición para el logro de la justicia social, además de ser un requisito previo necesario y fundamental para la igualdad, el desarrollo y la paz" (10).

En la actualidad, "el esquema político y la comunidad internacional, han realizado un retorno a la visión original de los derechos humanos como un conjunto indivisible, donde la Organización de las Naciones Unidas (ONU), dentro del Programa de las Naciones Unidas para el desarrollo, manifiestan su compromiso por el respeto a la indivisibilidad y a la no jerarquización de los derechos humanos, lo que permitirá que millones de personas puedan obtener el disfrute pleno de sus derechos" (9).

No obstante, la igualdad de derechos entre mujeres y hombres, proclamada en leyes, códigos, declaraciones nacionales e internacionales y el discurso político, se observan situaciones donde la inequidad se hace evidente de forma abierta y aún es más habitual observar desigualdad por género, de forma encubierta, lo que dificulta el abordaje de este fenómeno con el fin de erradicarlo y se habla de derechos de las mujeres y derechos de los hombres, cuando en términos legales e ideológicos ni siquiera se tendría que realizar esa diferencia.

Algunas de las diferencias de derechos humanos entre mujeres y hombres son señaladas por la ONU, ya que 
dicho organismo menciona que en el trascurso de la vida de las mujeres, se ven restringidas por actitudes discriminatorias, estructuras sociales y económicas injustas, además, en algunos países también por la falta de recursos, lo cual impide su participación plena y equitativa. Asimismo, la práctica de la selección prenatal del sexo, las tasas de mortalidad más elevadas y las tasas inferiores de matrícula escolar para las niñas en comparación con los niños, sugieren la preferencia por el hijo, limitando el acceso de las niñas a los alimentos, la educación y la atención de la salud. Además, agrega que es necesario reconocer la dignidad humana y el valor de las niñas, ya que la violencia contra la mujer empieza desde la niñez, puesto que desde etapas tempranas son objeto, con frecuencia, de ciertas formas de explotación y discriminación (10).

Al respecto, la literatura evidencia que parte de las diferencias existentes entre mujeres y hombres en cuestión de los derechos humanos, recaen en la violencia del hombre hacia la mujer, ya que dicha situación es ubicua y sin duda preocupa a los gobiernos y agrupaciones observantes de los derechos humanos, por lo anterior en Belém do Pará, Brasil, durante la Convención Interamericana para prevenir, sancionar y erradicar la violencia contra la mujer, se afirmó que la violencia contra la mujer, constituye una violación de los derechos humanos y las libertades fundamentales y limita total o parcialmente el reconocimiento, goce y ejercicio de los derechos y libertades de la mujer; los estados participantes declararon estarconvencidos deque la eliminación de la violencia contra la mujer es condición indispensable para su desarrollo individual y social y su plena e igualitaria participación en todas las esferas de vida ${ }^{(11)}$.

Conforme a lo anterior, los países copartícipes de la Convención Interamericana para prevenir, sancionar y erradicar la violencia contra la mujer, trabajan creando leyes y aplicándolas en pro de la igualdad entre mujeres y hombres, sin embargo, en países como Guatemala y México, entre otros, la violencia contra la mujer es una deuda pendiente entre las mujeres y los gobiernos, quienes parecen no tener una forma clara de actuación, para la resolución de esta problemática ${ }^{(12)}$.

La pobreza constituye otro tipo de atropello a los derechos humanos, especialmente de las mujeres, ya que "muchas mujeres carecen de los recursos y del poder económico necesario para cuidar de su familia y de sí mismas, incluso para decidir sobre su propia vida" (12).La tasa de analfabetismo femenino sigue siendo alta, especialmente para adultas mayores, mujeres indígenas y para aquellas que viven en zonas rurales. El 7.6\% de las mujeres mayores de 15 años son analfabetas, comparado con el $4.8 \%$ de los hombres ${ }^{(12)}$ y como consecuencia, más mujeres que hombres viven en situación de pobreza y son dependientes durante la vejez ${ }^{(13)}$.
La profesión de enfermería no permanece al margen de estas situaciones, ya que, el Consejo Internacional de Enfermeras (CIE) dentro de su Código Deontológico declara que es inherente a la enfermería el respeto de los derechos humanos, incluidos los derechos culturales, el derecho a la vida y a la libre elección, a la dignidad y a ser tratado con respeto, asimismo expone que en los cuidados de enfermería no hay restricciones en cuanto a consideraciones de edad, color, credo, cultura, discapacidad o enfermedad, género, orientación sexual, nacionalidad, opiniones políticas, raza o condición social, y afirman que uno de los compromisos de la enfermería con las personas, las familias y las comunidades es promover un entorno en el que se respeten los derechos humanos ${ }^{(14)}$.

\section{Derechos civiles}

Los derechos civiles están destinados a la protección de los seres humanos, contra cualquier agresión de un órgano público, aseveran que toda persona tiene derechos y libertades fundamentales sin distinción de raza, sexo, color, idioma, posición social o económica y tiene derecho a la vida, a la libertad a la seguridad jurídica, sostienen que nadie estará sometido a esclavitud o servidumbre a torturas ni a penas o tratos crueles, inhumanos o degradantes, ni se le podrá ocasionar daño físico, psíquico o moral, así como, nadie puede ser molestado arbitrariamente en su vida privada, familiar, domicilio o correspondencia, ni sufrir ataques a su honra o reputación ${ }^{(15)}$.

Los derechos civiles afirman quetoda persona puede circular libremente y elegir su residencia, en caso de persecución política, toda persona tiene derecho a buscar asilo y a disfrutar de él, en cualquier país, los hombres y las mujeres tienen derecho a casarse y a decidir el número de hijos que desean, todo individuo tiene derecho a la libertad de pensamiento y de religión, todo individuo tiene derecho a la libertad de opinión y expresión de ideas y toda persona tiene derecho a la libertad de reunión y de asociación pacífica ${ }^{(15)}$.

Lo anterior, tiene antecedentes en la declaración de la independencia de los EstadosUnidos en 1776 y en la Revolución Francesa de 1789, siendo asumida luego por el constitucionalismo clásico y contemporáneo, por el cual, se reconoce la igual naturaleza y atributos esenciales a todos los seres humanos. Esta dimensión, en perspectiva histórica, lleva a eliminar la esclavitud como expresión del desconocimiento de la dignidad humana y la igualdad esencial de las personas. Lo anterior, se reflejó tempranamente en el ordenamiento jurídico chileno, ya que, en 1811 declaró la libertad de vientres y la Carta Fundamental de 1823 abolió la esclavitud (16).

El 2 de mayo de 1948, se efectuó la Convención Interamericana sobre Concesión de los Derechos Civiles a la Mujer, realizada por la Organización de Estados Americanos (OEA), en Bogotá, Colombia, y ahí se declaró entre 
otras cosas, que: "la Mujer de América, mucho antes de reclamar sus derechos, ha sabido cumplir noblemente todas sus responsabilidades como compañera del hombre", lo anterior, deja ver la perspectiva androcéntrica en la que se redactó esta convención, que otorgan a forma de regalo los derechos civiles a las mujeres, puesto que han demostrado merecerlos, por acompañar al hombre (17).

Mientras que en 1966 se adoptó el Pacto Internacional de Derechos Civiles y Políticos, y a esa fecha ya había conciencia entre sus redactores de que el objetivo de conseguir la igualdad entre mujeres y hombres era difícil, especialmente porque en contra de su logro conspiraba el peso inmenso de la cultura, donde las mujeres tenían una clara posición de subordinación respecto a los hombres. La rebajada posición en la sociedad de las mujeres frente a los hombres, era tan evidente que los redactores del Pacto Internacional de los Derechos Civiles consideraron necesario contemplar además de las normas generales que incluían la no discriminación, entre otras causas en razón del sexo, una disposición que prohibía específicamente la discriminación en contra de la mujer, con el fin de que fuera explícito que el catálogo de los derechos humanos. Así el artículo tercero del Pacto establece que los Estados partes, se comprometen a asegurar a los hombres y a las mujeres igual ${ }^{(18,19)}$.

En cuanto a la legislación vigente en Chile, el artículo 349 del Código Civil de Comercio, señala que"puede celebrar el contrato de sociedad toda persona que tenga capacidad para obligarse. El menor y la mujer casada que no esté totalmente separada de bienes necesitan autorización especial para celebrar una sociedad colectiva. La autorización del menor será conferida por la justicia ordinaria, y la de la mujer casada por su marido." Lo que significa que las mujeres casadas por el régimen matrimonial de sociedad conyugal, no pueden concluir contratos de sociedad sin la previa autorización de su cónyuge, por lo que algunos organismos internaciones y expertos nacionales solicitan al gobierno chileno la modificación de este artículo ya que las normas civiles que regulan la capacidad jurídica de la mujer casada en sociedad conyugal están en clara oposición con el principio de igualdad ${ }^{(20-22)}$. De la misma forma hasta 1981 en España una mujer no podía tener una cuenta corriente, ni solicitar un pasaporte, sin permiso de su marido ${ }^{(23)}$.

Mientras que la Ley No. 10.783 del Uruguay, aprobada en el año 1946, referente a la capacidad civil de la mujer, especifica que la mujer y el hombre tienen igual capacidad civil, la mujer casada tiene la libre administración y disposición de sus bienes propios, dé sus frutos, del producto de sus actividades y de los bienes que pueda adquirir, enfatizando en el artículo 10, que ambos cónyuges contribuirán a los gastos del hogar, proporcionalmente a su situación económica ${ }^{(24)}$.
Sin embargo, siguen existiendo restricciones en algunos países en cuanto a diferencias puntuales entre mujeres y hombres, por ejemplo: los requisitos para contraer matrimonio, la patria potestad de los hijos, en ciertos tipos penales y en el acceso a la administración de justicia (25).

Una de las más grandes diferencias, es la mayor intervención de los hombres en los aspectos públicos de la sociedad, por lo que, existe conciencia de la necesidad de una mayor participación de las mujeres en política y al respecto la Organización de Estados Americanos (OEA) señala que: "El concepto de la democracia sólo asumirá su verdadero y dinámico significado cuando las políticas y la legislación nacional sean decididas conjuntamente por hombres y mujeres, tomando en cuenta, de manera equitativa, los intereses y las aptitudes de ambos sectores de la población" (26).

Con todo, la representación de la mujer en las instituciones democráticas aún no ha alcanzado esta paridad en el hemisferio. Por ejemplo, según la OEA, hasta octubre del 2002, en los congresos nacionales de las Américas, la representación de la mujer llegaba sólo a 17.6 \%. Esta cifra sitúa esta región como una de las regiones con la más alta representación de la mujer en los parlamentos, superada solamente por los países nórdicos. Por otra parte, lo esencial no es sólo el aspecto cuantitativo de su participación en la política, sino el impacto y el poder real que puedan tener. Igualmente preocupante, es el continuo descenso en muchos países del hemisferio, de la participación electoral de la mujer en las zonas rurales (26).

De forma semejante al caso de los derechos humanos, enfermería establece dentro de su código de ética, el respeto por los derechos civiles, enfatizando que "el derecho a la vida es el primero y más elemental de todos los derechos que posee la persona, un derecho que es superior al respeto o a la libertad del sujeto, puesto que la primera responsabilidad de su libertad es hacerse cargo responsablemente de su propia vida. Para ser libre es necesario vivir. Por esto la vida es indispensable para el ejercicio de la libertad" (27).

Por lo anterior, la posición del Consejo Internacional de Enfermería (CIE) ante la tortura, adoptada en 1989, prohíbe que las enfermeras colaboren en modo alguno con la tortura y exhorta a las organizaciones nacionales de personal de enfermería a que establezcan mecanismos que sirvan para apoyar a aquellos profesionales que se encuentren en situaciones difíciles. Asimismo, el CIE considera que la participación directa o indirecta de la enfermera en la preparación para la ejecución por pena de muerte y en la ejecución misma, autorizada por el Estado, es una violación al código deontológico profesional. Además, el CIE exhorta a las asociaciones de miembros para que trabajen a favor de la abolición de la pena de muerte ${ }^{(28)}$. 
Asimismo, la profesión de enfermería detalla el rol de la enfermera en la atención de detenidos y presos políticos y comunes, declara que "...las enfermeras, en conocimiento de todo caso de tortura física o mental a presos comunes y políticos, den todos los pasos necesarios, incluyendo la denuncia a organismos competentes nacionales $\mathrm{y} / \mathrm{o}$ internacionales". También rechaza la petición de que el personal de enfermería desempeñe labores propias del personal de seguridad, como la realización de registros corporales por motivos de seguridad ${ }^{(28)}$.

La enfermera en salud publica Lavinia Dock (1858-1956) estuvo comprometida con la búsqueda de la igualdad de derechos civiles de las mujeres como el derecho al voto, además pugno por igualar la profesión de enfermería a las otras del área de la salud, ya que denunció que la combinación poderosa de dominio masculino y discriminación sexual que impedía el reconocimiento de las enfermeras como profesionales iguales que los médicos. Luchó también por el derecho a la práctica independientede la enfermería, incorporando una visión social a la profesión y enfatizó sobre la importancia de la participación de la enfermera con el rol de abogada de los pacientes, ya que concibió a la enfermera como agente político para el cambio y peleo contra los prejuicios masculinos (29).

\section{Derechos laborales}

Los derechos laborales son elementos esenciales de los derechos humanos fundamentales, tanto los civiles y políticos como los económicos, sociales y culturales" (30).

El nacimiento de la Organización Internacional del Trabajo (OIT) en 1919, la redacción de las primeras normas internacionales del trabajo, el establecimiento de los procedimientos de control de la OIT y la Declaración de Filadelfia en 1944, tuvieron gran influencia en la redacción de la Declaración Universal de los Derechos Humanos realizada en 1966, gracias a ello los derechos laborales se incluyen en el grupo de los derechos humanos ${ }^{(31)}$.

La OIT desde 1951, decretó la igualdad de remuneración entre las mujeres y los hombres por un trabajo de igual valor y en 1958 estableció la norma contra la discriminación donde se prevé la adopción de una política nacional destinada a eliminar toda discriminación en materia de empleo, formación y condiciones de trabajo que esté basada en motivos de raza, color, sexo, religión, opinión política, ascendencia nacional u origen social, y a promover la igualdad de oportunidad y de trato ${ }^{(32)}$.

El protocolo adicional a la Convención Americana sobre los derechos humanos en materia de derechos económicos, sociales y culturales, "Protocolo de San Salvador", adoptado en el año 1988, establece en los artículos $6^{\circ}$ y $7^{\circ}$, el derecho al trabajo, en condiciones justas, equitativas y satisfactorias, donde se incluye entre otras cosas, que toda persona tiene derecho al trabajo para llevar una vida digna y decorosa a través del desempeño de una actividad lícita libremente escogida o aceptada, asimismo, incluyen el compromiso de los estados de ejecutar y fortalecer programas que coadyuven a una adecuada atención familiar, encaminados a que la mujer pueda contar con una efectiva posibilidad de ejercer el derecho al trabajo en las condiciones antes mencionadas ${ }^{(33)}$.

En muchos casos la realidad Latinoamérica de las mujeres se ha transformado, especialmente en relación a sus roles ya que estos han cambiado de ser cuidadora a principal proveedora, lo que llevo a modificar las relacionesy jerarquías de la familia tradicional, sin embargo, lo anterior, no se tradujo en independencia y desarrollo profesional para las mujeres, sino que generó desigualdades, discriminación, violencia y exclusión social, porque su ingreso al ámbito del trabajo no produjolos cambios necesarios en las pautas culturales de la sociedad, lo anterior, condujo a los empleadores a promover diversos tipos de precariedad laboral para las mujeres, con la justificación de lograr una supuesta flexibilidad del puesto de trabajo (34).

El atropello de los derechos laborales de las mujeres, es más evidente que el de los hombres, por ejemplo, en el caso del trabajo a domicilio, realizado en un $80 \%$ por mujeres donde las mismas no están contratadas formalmente por una empresa, por lo tanto, no cuentan con salario formal, carecen de protección social, asumen en sus hogares los costos de infraestructura, ponen en juego sus relaciones y recursos propios, y sus horarios se extienden sin límites. Lo anterior es señalado por algunos autores como "las reformulaciones postmodernas de la sobreexplotación, que hacen del empleo precario la bisagra entre las ganancias empresariales y la pobreza de quienes las generan con sus cuerpos" (12).

Por otro lado, a nivel mundial, el sector agrícola no es la excepción, ya que en muchos lugares los trabajos estacionales o de temporada no están sometidos a ninguna forma de regulación, incorporando subcontratistas, situación que permite abusos de poder en este modelo de trabajo estacional que, con variaciones, retrotrae a formas de esclavitud supuestamente erradicadas, aunado a los riesgos a la salud como lesiones, intoxicaciones por trabajar expuestas a químicos tóxicos sin protección, los trastornos músculo-esqueléticos por posturas forzadas propias de la recolección, el estrés u otras formas de compromiso de su salud psicológica por la carga de trabajo y el acoso laboral y/o sexual, forman parte de la realidad de las mujeres que trabajan en estas cosechas. La situación de millones de trabajadoras rurales en el planeta evidencia la brecha entre nociones discursivas y justicia (12).

Además, once millones de mujeres en América Latina y el Caribe desempeñan trabajo doméstico remunerado, 
generalmente con los niveles más bajos de salario y de protección jurídica y social. Al no garantizar protección social ni ejercicio de los derechos laborales, exigen que las trabajadoras aumenten el horario y la intensidad de su trabajo. En Chile, desde 1992 a 2000, mientras el PIB crecía $7 \%$ anual, las asalariadas del quintil más pobre, sin contrato de trabajo formal, aumentaron de un $29 \%$ a un $58 \%$, y las sin cotizaciones previsionales subieron de un $62.7 \%$ a un $68.4 \%$, cifras notablemente superiores a las reportadas respecto de los trabajadores hombres.Aunado a lo anterior, el trabajo doméstico no pagado, constituye también un factor de desigualdad, donde la balanza esta recargada hacia la mayor responsabilidad de la mujer en este rubro. Ante esto la plataforma de Beijing en 1995, planteó recomendaciones y objetivos orientados a la valoración del trabajo doméstico no remunerado y también a su reconocimiento y redistribución entre los sexos ${ }^{(12)}$.

Al mismo, tiempo las migraciones tanto a nivel nacional como internacional se han feminizado. La migración femenina ha pasado a constituir una estrategia económica para las familias. Millones de mujeres de América Latina se encuentran en riesgo por el hecho de ser mujeres y estar aisladas de sus culturas y hogares de origen. En la frontera del Sur de México, durante su migración, entre el 60 y 70\% de las mujeres son víctimas de violencia y acoso sexual de diferente magnitud ${ }^{(12)}$.

Sin embargo, "los derechos laborales no son un tema recurrente en los pronunciamientos de la Comisión Interamericana de Derechos Humanos (CIDH) y de la Corte Interamericana de Derechos Humanos (CorteIDH), cuyo motivo no es la ausencia de violaciones a estos derechos, sino la gravedad de otras violaciones a los derechos humanos, como el derecho a la vida y a la integridad de las personas. La mayoría de los pronunciamientos de la CIDH o de la CorteIDH, se refieren a la violación del derecho a la vida e integridad física de los líderes sindicales asesinados o desaparecidos, o a la vulneración de garantías judiciales y protección judicial de trabajadores despedidos, dejando un poco de lado la evidente vulneración al desarrollo progresivo de derechos económicos y sociales de esos trabajadores" (35).

Enfermería, como profesión predominantemente femenina, ha estado envuelta en discriminación por género desde sus inicios, ya que a través de la historia se puede observar que las características vinculadas a ser mujer se ven claramente reflejadas en el desarrollo de la profesión de enfermería,obstaculizando este proceso y en las cualidades exigidas a quienes la ejercen ${ }^{(36)}$, sin embargo, a la fecha es notoria la inclusión de hombres dentro de la profesión, los cuales en algunos casos destacan sobre las mujeres ocupando puestos gerenciales dentro de las instituciones de salud, lo que retrotrae al estereotipo de que el hombre es del espacio público y la mujer del privado.
Las condiciones de violencia imperantes en los recintos laborales, es preocupante para le enfermería, evidenciada por las múltiples investigaciones que se han desarrollado en la actualidad respecto al tema, no sólo sobre violencia física, sino también de otras formas de violencia más sutiles como el mobbing o la inequidad salarial que también es considerada una forma de violencia laboral, existiendo una clara y documentada discriminación de género ${ }^{(37)}$.

\section{Derechos sexuales y reproductivos}

"Los derechos sexuales y reproductivos son un conjunto de derechos que se relacionan con la sexualidad y la reproducción de las mujeres y los hombres. Son los derechos que tienen todas las personas, sin discriminación de ningún tipo a tomar decisiones con libertad y sin violencia. Es el derecho a tener la posibilidad de alcanzar el máximo bienestar y la mejor calidad de vida" (38). El concepto de derechos sexuales y reproductivos fue introducido por primera vez en la Plataforma de Acción de la Cuarta Conferencia Mundial sobre la Mujer en Beijing en $1995^{(39)}$, donde se reafirmó la necesidad de protección específica a las mujeres en este sentido.

La Asamblea General de la Asociación Mundial de Sexología reunida el 26 de agosto de 1999, durante el Congreso Mundial de Sexología en Hong Kong, República Popular China, declara que los derechos sexuales incluyen el derecho a la libertad sexual, autonomía, integridad y seguridad sexuales del cuerpo, privacidad, equidad, placer, expresión sexual emocional, libre asociación sexual, toma de decisiones reproductivas, libres y responsables, información basada en el conocimiento científico, educación sexual integral y atención de la salud sexual (40)."Los derechos sexuales son concebidos como derechos fundamentales porque se encuentran vinculados estrechamente a la libertad. En ellos se pone de relieve el derecho de los sujetos, llámense mujer u hombre, a la autodeterminación en el ejercicio de la sexualidad, lo que comprende la libertad en relación a la tendencia sexual y el derecho a la información sobre la sexualidad y la educación sexual" (41).

El observatorio para la protección de los derechos humanos en América, señala que en países como Colombia, Guatemala, México y Nicaragua, las líderes que encabezan la defensa de los derechos humanos de las mujeres son objeto de ataques y amenazas, particularmente en el contexto de denuncia de violencia contra las mujeres y reivindicación de derechos sexuales y reproductivos. En Nicaragua donde el aborto terapéutico esta criminalizado, las organizaciones de los derechos de las mujeres siguen teniendo hostigamiento judicial, amenazas y agresiones. En el 2009, continuo el alto número de casos de violencia contra las mujeres en México y Guatemala, donde se registran importantes tasas de crímenes de feminicidio, y las defensoras de los derechos humanos, se han convertido en víctimas, como en el caso de la organiza- 
ción Sobrevivientes de Guatemala y de mujeres periodistas de México, así como en Colombia, donde las mujeres defensoras de los derechos de las mujeres en situación de desplazamiento forzado están particularmente en el blanco de las amenazas. La misma situación se reporta en países como Cuba, Perú y Venezuela ${ }^{(42)}$.

La prohibición del aborto terapéutico, constituye una diferencia entre la igualdad de derechos de las mujeres y los hombres, en el caso de Chile, este es uno de pocos países del mundo donde aún es ilegal el aborto terapéutico. El Proyecto Aborto Terapéutico de Chile, postula que la interrupción voluntaria de un embarazo por violación, incesto o inviabilidad fetal debe ser garantizada por la constitución y las leyes, atendida por los servicios públicos, cuando se presentan circunstancias de especial gravedad para la integridad física y psicológica de una mujer. Y entiende esta garantía como un derecho humano de las mujeres, instauradas en el valor de sus vidas y en principios de justicia social, el cual es vulnerado desde 1989, año en que el aborto por razones terapéuticas fue convertido en delito, sin que la vigencia de la democracia haya logrado revertir la situación ${ }^{(43)}$.

El observatorio de equidad de género en salud-Chile, reporta en el informe 2007-2008, en cuanto a salud sexual y reproductiva, una tasa de mortalidad materna que se aproxima a 20 muertes por 100.000 nacidos vivos, donde se destaca que $15 \%$ de las muertes fueron por aborto, que son indicación de aborto terapéutico, como el embarazo ectópico y embarazo molar ${ }^{(44)}$.

En cuanto al embarazo adolescente el desafío es grande en toda América Latina y se asocia a un aumento en la brecha de desigualdad entre mujeres y hombres, fundamentalmente en relación a las posibilidades de continuidad en la educación y acceso al mercado laboral. Una demostración de lo anterior, son los resultados que arroja la encuesta CASEN 2009 en Chile, donde resalta que mientras 39,240 mujeres entre 10 y 19 años no asistían a un establecimiento educacional por situación de embarazo o de maternidad, sólo 1,980 adolescentes hombres no asistían a un establecimiento educacional por situación de paternidad ${ }^{(45)}$.

Además, existe evidencia de que los países de América Latina y el Caribe han presentado cifras preocupantes respecto de la prevalencia de violencia sexual, embarazos no deseados y enfermedades de transmisión sexual. Esto refleja, la necesidad generalizada de información y educación en sexualidad. Sumado a esto, "la inequidad en el acceso a los servicios de salud hace que muchas niñas y mujeres no pueden obtener la atención que requieren para cuidar y recuperar su salud sexual. También, las limitaciones en actitudes y aptitudes del personal de salud hacen que no se genere una relación empática, necesaria en este proceso una vez que se han superado los problemas en el acceso. La situación de mujeres que son víctimas de violencia sexual pero que, al solicitar atención en las instituciones de salud, no encuentran la respuesta adecuada, hace que se reproduzca el ciclo crónico de agresión ${ }^{(40) "}$.

A la problemática mencionada anteriormente, se le suman discusiones contemporáneas, como la tecnología para la infertilidad, la contratación de úteros portadores, la donación de óvulos, el congelamiento y clonación de embriones, la significación de la paternidad y maternidad en estas situaciones, la maternidad y paternidad en la formación de familias homosexuales, la subjetividad del placer sexual, entre otras. Lo que implica el principio de aceptación de la diversidad y la búsqueda de consensos puntuales, partiendo de la misma diversidad y variedad de visiones, necesidades y experiencias de las mujeres y los hombres, entrelazadas por sus propias diferencias. Ante el irrespeto a los derechos sexuales y reproductivos, enfermería ha tenido una actitud clara y es evidente la incumbencia profesional en este sentido ya que "la defensa de los derechos sexuales supone también la defensa de la libertad y la equidad: libertad para decidir y equidad de acceso a todos los medios necesarios para su ejercicio como información, educación sexual y servicios de salud sexual" (41).

\section{CONSIDERACIONES FINALES}

Los derechos civiles se encargan de la protección de los seres humanos contra cualquier agresión, sin embargo, todavía existen argumentos sexistas en algunos países que propician hacer distinción entre mujeres y hombres lo que resulta en que la mayoría los espacios públicos son ocupados por los hombres.

Enfermería pugna por el derecho a la vida, libertad y justicia, destacando la activista Lavinia Dock enfermera en Salud Pública, quien luchó por la equidad de derechos civiles y por igualar a la profesión de enfermería a las otras del área de la salud, enfatizando en la importancia de ejercer el rol de abogacía para los usuarios.

Entre las diferencias de derechos laborales por género, destaca las mejores remuneraciones por un mismo trabajo emitidas a los hombres, las precarias condiciones de trabajos predominantemente femeninos conjugados a la ejecución de trabajo doméstico no pagado.

Es importante buscar la salud sexual y reproductiva de mujeres y hombres, sobre todo en los temas tradicionalmente abordados pero no resueltos, como el aborto terapéutico, el embarazo adolescente y la anticoncepción, sumado a lo anterior temas más contemporáneos como la infertilidad, las familias homosexuales, entre otros, lo que implica una aceptación a la diversidad. El respeto por los derechos es un tema de todos. La igualdad de dere- 
chos entre mujeres y hombres está estipulada en múltiples tratados, convenciones y legislaciones, sin embargo, todavía existen diferencias concertadas en algunas leyes lo que revela la perspectiva androcéntrica con la que fueron redactadas.

Las mujeres a través de la historia han luchado por la igualdad de derechos, no obstante, siguen existien- do actitudes discriminatorias que resultan en violencia, pobreza y peores condiciones de vida en relación a los hombres. La postura de la profesión de enfermería, es pugnar siempre por el respeto a los derechos humanos sin discriminación de ningún tipo.

\section{REFERENCIAS BIBLIOGRÁFICAS}

1.- Staff W. Mujer y derechos humanos. KO'AGA ROÑE'ETA [Internet] 1998; se.viii [Consultado Septiembre del 2011]. Disponible en: http://www.derechos.org/koaga/ viii/staff.html

2.- Caro M. Derechos laborales y de salud en el trabajo de las temporeras en Chile. Herramienta básica para el ejercicio de la ciudadanía. Colección educación ciudadana. Centro de estudios para el desarrollo de la mujer. 2da. Edición.2004. pág. 64.

3.- República de Chile. Constitución Política de la República. Especial para estudiantes. Editorial jurídica de chile. 2007. Santiago. 130 pág.

4.- Lincoln B. Derechos humanos y dimensión social en los regionalismos del siglo XXI. Construcción y perspectivas desde el espacio del Mercosur. Observatorio de políticas públicas de derechos humanos en el Mercosur. [Internet].[Consultado Noviembre del 2011]. Disponible en:http://www.observatoriomercosur.org.uy/libro/pdfs/Politicas_Publicas_de_DD_HH.pdf

5.- Plan de igualdad de oportunidades entre mujeres y hombres. 2000-2010[Internet]. [Consultado en Septiembre 2011] Disponible en: http://www.pnud.cl/areas/Género/Plan_nacional_igualdad_2000_2010.pdf

6.- Estrategia para la igualdad entre mujeres y hombres 2010-2015 [Internet]. [Consultado Octubre del 2011]. Disponible en: http://eur-lex.europa.eu/LexUriServ/LexUriServ.do?uri=COM:2010:0491:FIN:ES:PDF

7.- Gita S, Asha G, Piroska O. Sesgo de Género, Igualdad y Equidad. Incorporar la perspectiva de género en la equidad es salud. Análisis de la Investigación y las políticas. Publicación ocasional Numero 14. Organización Panamericana de la Salud: Oficina Regional de la Organización Mundial de la Salud; 2005. [Internet]. [Consultado 2011 Oct 12]. Disponible en:http://www.paho.org/Spanish/DD/PUB/PO_14_entire_book.pdf

8.- Bordarampe A. La igualdad entre hombres y mujeres es inherente a los derechos humanos. Red para el Desarrollo Integral de la Niñez y la Familia. Argentina.

9.- Derechos civiles y políticos. Choike.org. [Internet]. [Consultado Septiembre del 2011]. Disponible en: http://www.choike.org/nuevo/informes/1351.html

10.- Organización de las Naciones Unidas. Informe de la Cuarta Conferencia Mundial Sobre la Mujer. Beijing China 1995. [Internet]. [Consultado Octubre 2011]. Disponible en: http://www.un.org/womenwatch/daw/beijing/pdf/Beijing\%20full\%20 report\%20S.pdf

11.- Organización de los Estados Americanos. Comisión Interamericana de Derechos Humanos. Documentos Básicos en Materia de Derechos Humanos en el sistema Interamericano. Actualizado a enero de 2007. Washington, D.C: cidh; 2007.

12.- Matamala M. Apuntes para la reflexión y acción. La nueva realidad global y el derecho de las mujeres a la salud en ALC. Revista Mujer y Salud/ RSMLAC.2010; 3:22-37.

13.- CEPAL. Mujeres y Pobreza. Ficha informativa sobre género y desarrollo [internet] 
No. 2. [Consultado 2011 Oct 16]. Disponible en: http://www.cinu.org.mx/gig/Documentos/pobreza.pdf

14.- Consejo Internacional de Enfermeras. Código Deontológico para la profesión de enfermería. Suiza. Imprenta Fornara, 2006.

15.- Biblioteca del Congreso Nacional de Chile. Pacto internacional de derechos civiles y políticos; derechos civiles; derechos políticos. Decreto 778. [Internet]. [Consultado Enero 2012] Disponible en: http://www.leychile.cl/Navegar?idNor$\mathrm{ma}=15551$

16.- Nogueira A. El derecho a la igualdad ante la ley, la no discriminación y acciones positivas.AFDUDC, 2006; 10: 799-831

17.- Trejo-García E. Tratados Internacionales vigentes en México: relación de Legislaturas y/o Períodos Legislativos en que fueron aprobados [Internet]. [Consultado Octubre 2011]. Disponible en: http://www.diputados.gob.mx/cedia/sia/spe/ SPE-ISS-03-07.pdf

18.- Medina C. Las Naciones Unidas y el Desarrollo del Derecho Internacional: Derechos Humanos y Mujeres en el Texto y Jurisprudencia el Pacto Internacional de Derechos Civiles y Políticos. Sociedad Chilena de Derecho Internacional Estudios 1995.Santiago de Chile. Pág. 51-65.

19.- Diario Oficial de la República de Chile [Internet]. [Consultado octubre 2011] Disponible en: http://www.diarioficial.cl/

20.- Valenzuela M. Desafíos para la igualdad en el trabajo: Chile. OIT NOTAS. [Internet]. 2007; 1-4. [Consultado Octubre del 2011]. Disponible en: http://www.oitchile.cl/género/Chile.pdf

21.- Bello-Muñoz M, Morales-Jiménez M. Capacidad jurídica de la mujer casada en sociedad conyugal en relación con el principio de igualdad. [Tesis en Derecho]. Temuco: UC Temuco; 2006.

22. - Chile. Código de Comercio Chileno. [Internet]. [Consultado el 30 de Octubre del 2011]. Disponible en: http://www.nuestroabogado.cl/codcomercio.htm

23. - Monteso-Curto MP. Concepto de género, mainstreaming e igualdad de oportunidades. Rev ROL Enf 2010; 33(5):362-67

24.- República Oriental del Uruguay. Poder Legislativo. Ley N 10.783. Capacidad Civil de la Mujer. [Internet]. [Consultado 2011 Nov 13]. Disponible en: http://200.40.229.134/htmlstat/externos/derechosmujer/ley10783.PDF

25.- Comisión Interamericana de Derechos Humanos. Organización de los Estados Americanos. [Internet]. [Consultado 2011 Nov 13]. Disponible en: http://www. cidh.oas.org/women/Mujeres98/Capitulo3.htm

26.- Organización de Estados Americanos. La participación de la Mujer en los procesos políticos. [Internet]. [Consultado 2011 Nov 13] Disponible en: http://www. oas.org/OASpage/women/agenda_spa.htm

27.- Código de Ética para las enfermeras y enfermeros en México. IMSS. Secretaría de Salud. ISSSTE. [Internet]. [Consultado 2011 Dic 13]. Disponible en: http://www. salud.gob.mx/unidades/cie/cms_cpe/descargas/codigo_etica.pdf

28.- Amnistía Internacional. Personal de Enfermería y Derechos Humanos. 1997. EDAI. España. [Internet]. [Consultado en Enero del 2012].Disponible en:http:// www.hrea.net/erc/Library/display_doc.php?url=http\%3A\%2F\%2Fwww.hrea.org\%2Ferc\%2FLibrary\%2Fmedical_personnel\%2FA7500297_sp.pdf\&external=N

29.- Martínez-Ques A. Fernández-Romero F. El compromiso de una pionera con los derechos de las mujeres Lavinia Lloyd Dock (1858-1956). Index Enferm.2007; 16 (56):62-65. 
30.- Derechos Laborales de los Trabajadores. Educar Chile. [Internet]. [Consultado Enero 2012].Disponible en: http://www.educarchile.cl/Portal.Base/Web/VerContenido.aspx?ID $=198038$

31.- Cannesa M. Los derechos humanos laborales en el derecho internacional. Derecho PUCP. Pág. 349 -373.

32.- Organización Internacional del Trabajo. [Internet].[Consultado 2011 Oct 30]. Disponible en: http://www.lo.org/wcmsp5/groups/public/@dgreports/@ dcomm/@webdev/documents/publication/wcms_082363.pdf

33.- Organización de los Estados Americanos. Comisión Interamericana de Derechos Humanos. Documentos Básicos en Materia de Derechos Humanos en el sistema Interamericano. Actualizado a enero de 2007. Washington, D.C: cidh; 2007.

34.- Ortiz M. La equidad de género en la reforma laboral. Instituto de Investigaciones Jurídicas UNAM. [Internet]. [Consultado 2011 Nov 12] 227-247. Disponible en: http://www.bibliojuridica.org/libros/6/2505/14.pdf

35.- López-Patrón J. Los derechos laborales en el sistema interamericano de protección a los derechos humanos: la protección de los derechos económicos, sociales y culturales. Int. Law: Rev. Colomb. Derecho Int. Ildi. Colombia: 2008; 12: 183-216.

36.- Zúñiga-CareagaY; Paravic-KlijnT. El género en el desarrollo de la enfermería. Rev Cubana de Enfermería. 2009; 25(1-2). [Internet]. [Consultado Enero 2012].Disponible en: http://www.bvs.sld.cu/revistas/enf/vol25_1-2_09/enf091_209.htm

37.- Poblete-Troncoso M, Valenzuela-Suazo S. Enfermeras en riesgo. Violencia laboral con enfoque de género. Index Enferm. 2005; 14 (51):40-44

38.- Instituto Chileno de Medicina Reproductiva ¿Qué son los derechos sexuales y reproductivos? [Internet]. [Consultado Enero 2012].Disponible en: http://www. infojoven.cl/1-3.php

39.- Leyes contra el aborto en Chile. Un análisis desde los derechos humanos. Centro legal de políticas públicas. Foro abierto de salud y derechos reproductivos. [Internet].[Consultado 2011 Nov 14]. Disponible en:http://www.despenaliza. cl/encarceladas_parte1.pdf

40.- Montoya-Montoya G. La ética del cuidado en el contexto de la salud sexual y reproductiva. Acta bioeth. 2007; 13(2): 168-75. [Internet]. [Consultado Enero 2012] Disponible en: http://www.scielo.cl/scielo.php?scrip$\mathrm{t}=$ sci_arttext\&pid=S1726-569X2007000200003\&lng=es. doi: 10.4067/ S1726-569X2007000200003

41.- Valladares-Tayupanta L. Derechos sexuales. Convención Interamericana de los derechos sexuales y los derechos reproductivos. Uruguay: 2010; 53-72. [Internet]. [Consultado en Enero del 2012] Disponible en: http://www.convencion.org. uy/08Debates/Serias2/Lola\%20Valladares.pdf

42.- Observatorio para la protección de los defensores de los derechos humanos. Informe anual 2010. Américas [Internet] Consultado el 27 de octubre del 2011. Disponible en:http://www.fidh.org/IMG/pdf/OBS2010ES_Americas_defensores_ derechos_humanos_fidh.pdf

43.- Despenaliza. cl. Proyecto aborto terapéutico en Chile. [Internet]. [Consultado 2011 Nov 13]. Disponible en: http://www.despenaliza.cl/

44.- Eguiguren $\mathrm{P}$, Calvin M, Díaz X, Ferrer M, Iglesias M, Olavarría J. Observatorio de Equidad de Género en Salud-Chile: Una mirada a las políticas públicas. Rev Chil Salud Pública 2009: 13 (2):106-11

45.- Servicio Nacional de la Mujer. Gobierno de Chile. [Internet]. [Consultado 2011 Nov 5] Disponible en: http://portal.sernam.cl/ 